\title{
TEATRO EXPERIMENTAL INDEPENDIENTE (TEI) Y EL PEQUEÑO TEATRO MAGALLANES: HACIA LA INDEPENDENCIA DEL ACTOR
}

\section{TEATRO EXPERIMENTAL INDEPENDIENTE (TEI) AND THE PEQUEÑO TEATRO MAGALLANES: TOWARDS THE INDEPENDENCE OF THE ACTOR}

\author{
Agnieszka LISOWSKA \\ Doctora por la Universidad Autónoma de Madrid \\ lisowska.agnieszka@gmail.com
}

\begin{abstract}
Resumen: El presente artículo estudia la trayectoria del grupo Teatro Experimental Independiente, uno de los máximos representantes del Teatro Independiente en España. El trabajo se centra en la fase del auge de su desarrollo, vinculada con la actividad de la sala Pequeño Teatro Magallanes. Describe tanto los orígenes de la fundación del colectivo, como las bases de su funcionamiento, y presenta, además, las producciones realizadas y estrenadas en la época desde 1969 hasta 1974.

Abstract: This article examines the trajectory of Teatro Experimental Independiente, one of the leading representatives of the Independent Theatre in Spain. The work focuses on the boom phase of its development, linked to the activity of the playhouse Pequeño Teatro Magallanes. It describes both the origins of the formation of the group, and the foundations of their work, and also presents productions staged between 1969 and 1974.
\end{abstract}


Palabras clave: Teatro Independiente. Teatro Experimental Independiente. Pequeño Teatro Magallanes. El Método.

Key Words: Independent Theatre. Teatro Experimental Independiente. Pequeño Teatro Magallanes. Method acting.

\section{Preámbulo}

El movimiento del Teatro Independiente surgió como una idea y un propósito de renovación de la escena española. Los creadores españoles, inspirados por las diferentes disciplinas y prácticas artísticas, inician un nuevo capítulo en la historia del teatro en España, definido por una profunda reflexión sobre las formas y la capacidad de comunicación del arte teatral. Entre los colectivos que surgieron en esta época el Teatro Experimental Independiente destacó por su resistencia y capacidad para establecer un lugar teatral, reunir un público fiel y crear una sensibilidad teatral inspirada en los grandes nombres de la vanguardia teatral de la segunda mitad del siglo XX. Su famoso local de la calle Magallanes, número 1 , fue un centro de irradiación, que no solo resultó significativo para el desarrollo del propio grupo, sino también sirvió de refugio para otros colectivos independientes. La historia del TEl puede dividirse en tres fases que corresponden a la periodización del movimiento independiente propuesta por Alberto Fernández Torres (1987) y las épocas delimitadas por Ángel Berenguer (Pérez Jiménez, 1999). Habría, por lo tanto, una primera fase desde 1960 hasta 1969 (durante el período de Desarrollo) donde nace el Teatro Estudio de Madrid, el antecedente del TEl. La segunda fase abarca desde 1969 hasta 1976 (durante el período de Decadencia) y marca el auge de la actividad del grupo. Y por último, desde 1976 hasta 1977 (durante la época de la Transición) tiene lugar el final del TEl. El presente artículo se centra en la segunda fase del desarrollo del colectivo cuando el TEl, a través de su cooperativa teatral y su sala Pequeño Teatro Magallanes propone un nuevo paradigma basado en un teatro independiente y autónomo centrado en la emancipación del actor.

\section{Fundación del TEI}

El grupo TEl tiene sus orígenes en el Teatro Estudio de Madrid, que nace a partir de una voluntad colectiva de crear un nuevo sistema pedagógico, un tipo de enseñanza hasta ese momento inexistente en España, que educara al actor y que le ayudara a dominar la expresividad del cuerpo y de la voz, para ofrecer al público un teatro de calidad. La escuela, fundada en 1960 por Elizabeth Buckley, José Sáez de Vicuña y Miguel Narros, con la colaboración de William Layton $^{341}$, se convertirá en referencia destacada en España en la introducción del Método de Stanislavski propagado por las escuelas americanas. El éxito más sonado y aplaudido del TEM, fue la obra Proceso por la sombra de un burro, de F.

\footnotetext{
${ }^{341}$ Además de estos nombres en diferentes fuentes documentales aparecen otras personas adscritas a la fundación del TEM. López Gómez (1965) cita al director argentino Rodolfo Beban como uno de los fundadores de la escuela. En cambio, en la entrevista de Alonso de Santos (1981) Beban aparece mencionado por Layton como uno de los primeros alumnos del TEM. Por otro lado, el mismo artículo menciona el nombre de Paco Molero como uno de los iniciadores del TEM. El mismo Molero en Díaz Sande (1980) figura como Paco Velero.
} 
Dürrenmatt estrenada en $1965^{342}$. Siendo la primera pieza montada a base de improvisación causó asombro y admiración tanto entre el público como entre la crítica. Se valoró sobre todo el nuevo tipo de teatro que el TEM venía anunciando desde hace tiempo: teatro entendido como una manera de creación artística. El triunfo del Proceso de la sombra de un burro le lleva al TEM a ganar en 1967 el Premio Nacional de Teatro y da un empujón hacia la posición de jóvenes renovadores del teatro español.

Entre finales de 1968 y principios 1969 el grupo brillante de la escuela decide separarse y crear su propia compañía. Esta decisión tiene sus orígenes en el éxito de la obra de Dürrenmatt que provoca enfrentamientos ideológicos y técnicos dentro del TEM. Empieza a crearse un desequilibrio: ¿qué hacer ahora?, ¿seguir estrenado espectáculos o seguir mejorando el taller en la escuela? La gota que colmó el vaso fue el montaje de la obra Terror y miseria del III Reich de Bertolt Brecht, que José Carlos Plaza planteó como el siguiente estreno. En aquel momento Brecht era uno de los autores adversos al régimen y hasta la época del aperturismo en el año 1974 la mayoría de los dramas del alemán tenía problemas con la censura. La dirección del TEM, muy consciente del riesgo que el montaje podía suponer, decidió suspender el estreno, a pesar del apoyo por parte del Instituto de Cultura Hispánica. En este momento quedó muy claro que la dirección de la escuela y sus alumnos tenían otras finalidades. La escuela, que quería continuar con la formación de actores como prioridad y temiendo las repercusiones externas que podría provocar presentar la obra decidió no participar. En cambio algunos de los actores, liderados por José Carlos Plaza, querían estrenar la obra independientemente de cualquier consecuencia política. El director lo veía muy claro: "El problema principal y concreto de la separación fue Terror y miseria del III Reich. Nosotros lo habíamos montado y queríamos estrenarlo, cayera quien cayera. Entonces el TEM no quiso estrenar la obra. Nosotros lo hicimos, en un Colegio Mayor, aunque a las 24 horas fue prohibida por la censura" (Layton, 1972: 19). De esta forma, José Carlos Plaza, convertido en líder de la separación, crea una nueva compañía: Teatro Experimental Independiente.

Esta decisión es también consecuencia de un nuevo impulso que empieza a canalizarse por medio del movimiento independiente, para transformar el panorama teatral en España. Tal como indica Cornago Bernal (2000: 136), la especificidad y la diferencia de la nueva corriente en comparación con los anteriores movimientos residen en el desarrollo constante de una poética rigurosamente escénica que, aunque ligada a un compromiso social e ideológico, estaba ya lejos de actitudes culturalistas y eclécticas que presentaban los anteriores grupos, nacidos en su mayoría en ámbitos universitarios. Estas variaciones en el modelo tanto de creación como gestión teatral tienen su origen también en el cambio político y administrativo que se da en España. Como describe Fernández Insuela (1975: 303322), los años comprendidos entre 1966 y 1969 constituyen un importante período en la historia del teatro no comercial, que abarca la etapa entre la constitución de la Ley de Prensa e Imprenta y la caída del ministro Fraga. Fernández Insuela cita como característicos de esta etapa los hechos, recogidos en Pipirijaina (Búfalo, 1974: 1-2), que influyeron de manera directa en la fundación de varios colectivos nacidos en este período: más posibilidades de una estabilización económica, creación de circuitos de representación al margen del teatro comercial, búsqueda de un mayor contacto con la realidad social española unido a una mayor formación de los componentes de los grupos y finalmente un apoyo mayor por parte

\footnotetext{
${ }^{342}$ Otros estrenos del TEM son: Historia del zoo y Caja de arena (1963), Cuento para la hora de acostarse (1966), Noche de reyes (1967) y Electra (1968).
} 
de la burguesía liberal ${ }^{343}$. Estas características vienen reflejadas también en la opinión de Moisés Pérez Coterillo:

Es evidente que la historia del teatro independiente puede escribirse sobre una precisa escala cronológica de nuestra historia última y que las relaciones existentes entre las condiciones de vida establecidas por cada etapa de la Administración y el desarrollo real de la actividad de los grupos es innegable. No es casual que en 1968 se registre la fecha de fundación de buen número de grupos y que en las mismas fechas los montajes realizados alcancen mayor número y difusión [... (Pérez Coterillo, 1974:22-23).

Constituido el Teatro Experimental Independiente ${ }^{344}$ el grupo busca la apertura de un espacio propio. Sin embargo, por falta de suficientes medios económicos decide instalarse en el Colegio Mayor San Juan Evangelista. El grupo llega a un acuerdo con el director que les permite ensayar regularmente a cambio de que fueran encargados del Corral de Comedias, que llevaba las actividades teatrales.

El 15 de enero de 1969 José Carlos Plaza presenta al Director General de Cultura Popular y Espectáculos de Madrid la petición de registro del grupo en el Registro Nacional de Teatros de Cámara y Ensayo y Agrupaciones Escénicas no profesionales ${ }^{345}$, de acuerdo con el artículo 7 de la Orden Ministerial del 30 de mayo de 1962. En los estatutos adjuntos, Plaza presenta los siguientes fines y la estructura de la compañía:

Artículo 1.- El TEl se constituye como sociedad teatral, con el fin primordial de hacer teatro.

Artículo 2.- Se incorporarán las técnicas avanzadas y actuales de teatro, tratando de adaptarlas con una visión histórica y social.

Artículo 3.- - Su actividad se extenderá a los sectores de público que, por una u otra razón, no tiene acceso al fenómeno teatral.

Artículo 4.- L L constitución como compañía teatral profesional, a corto plazo, es el fin que perseguimos, para así poder llevar a efecto lo señalado en el artículo 3.

Artículo 5.- Se promocionará y fomentará cualquier actividad teatral, premios, publicaciones, traducciones, festivales etc., que estén de acuerdo con este reglamento, con las características que en su día se definan.

\footnotetext{
${ }^{343}$ Para más datos sobre el contexto teatral, puede verse e trabajo de José Romera Castillo (2011)," Sobre un teatro (en) vivo: el nuevo teatro en la escena madrileña (1970-1974)".

${ }^{344}$ Según José Carlos Plaza la palabra independiente se utilizó en un principio para marcar la ruptura con el TEM, luego la misma palabra ha servido para clasificar a todo el movimiento (Layton, 1972: 19). Sin embargo, tal y como indica Ciurans (2003: 14), en España la palabra empieza a utilizarse a principio de los años 1960. Una de las primeras publicaciones es la de Ricard Salvat quien utiliza la palabra independiente como sinónimo de la renovación y experimentación (Salvat, 1963). La denominación tiene su origen en Argentina, a principios de la década de los años 30, donde nace el Teatro del Pueblo, considerado el primer teatro independiente. Es importante señalar también que, en el caso de Cataluña, la denominación independiente conllevará también la recuperación de un teatro en lengua catalana.

${ }^{345}$ El expediente de la inscripción se encuentra en el AGA en el Registro Nacional de Teatros de Cámara y Ensayo y Agrupaciones Escénicas no profesionales, caja del año 1969.
} 
Artículo 6.- Se mantendrá contacto con otros grupos teatrales, nacionales y extranjeros que, por sus características se propongan fines similares.

Con fecha de 16 de abril de 1969 el TEl queda inscrito en el Registro Nacional de Teatros de Cámara y Ensayo y Agrupaciones Escénicas no profesionales. La nueva compañía empieza su actividad continuando las representaciones de Electra, espectáculo montado todavía bajo las siglas del TEM. Después, durante varios meses los actores acuden al Hospital de Ciempozuleos para ayudar al doctor Pablo Población en las sesiones de psicoterapia. Pasado el tiempo de trabajo con los enfermos, el grupo, convencido del valor dramático de las sesiones, al margen de su valor terapéutico, decide escribir un texto teatral. Población lo describe del siguiente modo: "Algún tiempo después se abrió ante nosotros la realidad de dos hechos evidentes: 1. Valor dramático intrínseco del psicodrama con independencia de su función terapéutica. 2. Sus amplias posibilidades como forma de expresión teatral" (Población, 1971: 305). La sesión se estrenó en el Teatro Bellas Artes el 26 de septiembre de 1969 con gran éxito, que la llevó a presentarse durante seis meses. Seguidamente, el 14 de junio de 1970 pasó a reponerse en el Teatro Marquina de Madrid. El gran interés de público y crítica fue además avalado con el premio del Ciclo de Teatro de Cámara y Ensayo, celebrado en 1970 en el Teatro Marquina. El día 5 de julio de 1970 tuvo lugar una función extraordinaria de La sesión, que fue representada junto con Castañuela 70 de Tábano, que también ganó el mismo premio.

El espectáculo fue un punto decisivo en la futura trayectoria del TEl por varias razones. En primer lugar, el montaje se convirtió en el primer gran éxito de la compañía, situando al TEl en la primera línea del movimiento independiente y desvinculando definitivamente al colectivo de su pasado con el TEM. Segundo, las representaciones de La sesión mejoraron la situación económica de la compañía, hasta tal punto que en 1971 abrirían su propio local. En tercer lugar, La sesión Ilevó al TEl a participar en el Festival Cero de San Sebastián, considerado por José Monleón el gran punto de inflexión del Teatro Independiente en España. Aunque el propio hecho fue muy importante, la intervención del grupo no pudo realizarse y el certamen no llegó a cumplir todas las expectativas ${ }^{346}$.

En la apertura del local también ayudó la intervención el 10 octubre de 1970 en la zarzuela, El último romántico de su tiempo, bajo la dirección de Gustavo Pérez Puig, en la adaptación de Enrique Llovet. La participación de los actores del TEl en este montaje, bien renumerada, subió su estatus económico y consolidó el grupo.

\section{Pequeño Teatro Magallanes: los inicios}

La época del funcionamiento del Pequeño Teatro Magallanes, que será la primera sala comercial de una compañía independiente en España ${ }^{347}$, es el período más fructífero en cuanto a producciones del TEl. En total son 13 montajes en un período comprendido entre julio de 1972 y junio de 1976. En estos cuatro años la época más intensa recae entre los años 1972-73, cuando la compañía realiza siete estrenos propios y presenta siete producciones

\footnotetext{
${ }^{346}$ Para más información sobre el Festival Cero véase Monleón (1970a, 1970b).

${ }^{347}$ Hubo, eso sí, salas (como el teatro Alfil en Madrid o el teatro CAPSA en Barcelona) que acogían con frecuencia a los grupos independientes, pero ninguna de carácter tan exclusivo y propiedad de una compañía, como fue el caso del Pequeño Teatro Magallanes.
} 
de otros grupos en la sala del Pequeño Teatro Magallanes. La necesidad de asentarse en un local que perteneciera al grupo estaba entre los miembros de la compañía desde sus inicios, sin embargo, después de dos años y cuatro estrenos, el TEl siente que para seguir su desarrollo necesita dar un paso más en su profesionalización:

Habíamos llegado a un momento en el que no podíamos continuar siendo amateurs, en peor sentido de la palabra. La gente no podía seguir en oficinas o dando clases de inglés para ganarse la vida, porque llega un momento en el que es necesario que el actor dedique el tiempo al conocimiento de su técnica. [...] La única manera de seguir estaba en conseguir un medio de vida que nos permitiera dedicar 24 horas al trabajo del grupo. Solo si los componentes del grupo eran profesionalmente independientes habríamos alcanzado una cierta independencia (Layton, 1972: 20).

En 1971 el grupo encuentra una sala en la calle Magallanes número 1. Aunque el arquitecto Pablo Carvajal se ocupó de transformar la sala de modo que esta pudiera cambiarse en cada montaje, con una capacidad de unas 80 butacas, según las normativas existentes desde 1918, por falta de capacidad suficiente, la sala no se podía clasificar como edificio teatral comercial y la única posibilidad para poder funcionar era registrarla como café-teatro. $^{348}$

Para el TEl la denominación del café-teatro nunca les resultó adecuada, ya que sus ambiciones iban más allá de un bar con espectáculos. Aunque el grupo tenía que registrar el local de esta forma, siempre intentaban huir del nombre café-teatro: "[...] no somos caféteatro, sino un teatro muy experimental. Estamos experimentando diariamente. Nadie se llame a engaño cuando venga aquí" (TEl, 1971: 132). En este punto es importante señalar, que a pesar de la denominación oficial que indicaba el registro, con el tiempo las carteleras oficiales incluyeron al Pequeño Teatro Magallanes dentro del circuito comercial mayoritario, presentando sus estrenos junto con los demás teatros comerciales.

El nuevo local se estrena en julio de 1971 con la obra Lo que te dé la gana, versión del musical estadounidense basado en la Noche de reyes, de Shakespeare, que marca el primer éxito de la sala con más de trescientas representaciones y muy buenas reseñas. El crítico de La Estafeta Literaria califica la obra del TEl como "un espectáculo inusitado, una isla brotada en el rutinario mar de nuestro teatro, una invención insólita, a gran distancia — para biendel teatro usual" (Álvaro, 1972: 213). Igualmente entusiasta se muestra el crítico del Nuevo Diario que considera la pieza "un espléndido y ordenado barullo de movimiento casi continuo y acelerado, un divertido lío - perfectamente dosificado- en el que se mezclan diálogos y canciones, carreras y sentencias de personajes famosos, gritos y marchas triunfales" (Álvaro, 1972: 213). Dos días más tarde se presenta una pieza menor de Martínez Ballesteros, titulada La muy legal esclavitud.

Desde el punto de vista práctico, la programación del Pequeño Teatro Magallanes fue la misma casi todos los días. Desde las diez de la mañana hasta las dos de la tarde, en grupos

\footnotetext{
${ }^{348}$ El fenómeno de los café-teatro era cosa habitual en París y Nueva York a principios de los años sesenta. A España llega al final de la década, con la madrileña Lady Pepa, dirigida por Concha Lorca, siendo su directora artística. Pionera en esta experiencia fue Barcelona con La Cova del Drac, que presentó algunos espectáculos de Jaume Vidal y María Aurelia Capmany. Entre 1970 y 1974, según Sánchez Sánchez (1997: 139-198), en Madrid se abrieron treinta y tres café-teatros (exceptuando el Pequeño Teatro Magallanes), de los cuales diecisiete llegaron solo a uno o dos estrenos y cerraron pronto sus puertas.
} 
divididos, se realizaban trabajos sobre la expresión, emoción y sobre la voz. Dentro de estos grupos dedicados a la formación dentro de la línea de la interpretación orgánica, uno se dedicaba a la preparación y el otro a la experimentación. Según los datos que aporta el diario $A B C$ (TEl, 1971: 132), en noviembre de 1971 en el Pequeño Teatro Magallanes había doce actores y seis profesores. Los profesores principales del laboratorio eran: William Layton, Arnold Taraborrelli y Pilar Francés. Tal y como indica José Carlos Plaza (Layton, 1972: 142), entre los alumnos también aparecían profesionales que, aunque no pertenecían al grupo, participaban en las clases para desarrollar su interés por las nuevas investigaciones teatrales. Según el director, entre ellos estaban: Ana Belén, Silvia Vivó, Enriqueta Carballeira, Tina Sainz, Marisa Paredes, Rafael Guerrero, Eusebio Poncela, Ramón Pons, Massiel, etc.

En cuanto al mecanismo interno de funcionamiento, el TEl seguía aplicando el sistema de cooperativa teatral que ya había declarado en el reglamento adjunto al registro y convirtió su Pequeño Teatro Magallanes en una sociedad anónima, cuya mayoría de acciones pertenecía al propio TEl. Para el movimiento independiente el cooperativismo fue el modelo administrativo y artístico más coherente, ya que les permitía llegar, por un lado, a la profesionalización del trabajo, y, por otro, convertía la prolongada convivencia de los miembros del grupo en un modo de vida. La creación colectiva fue para los grupos una fórmula eficaz que permitía cambiar el proceso de construcción teatral en un acto de elaboración conjunta. Dentro de este fenómeno cada uno de los miembros del grupo podía hallar un marco conveniente para desempeñar su labor creativa, que a su vez le permitiera expresarse y manifestarse.

En este sentido, el TEl en la mayoría de los montajes rechazaba destacar nombres de director, actores, escenógrafos, para mostrar lo colectivo como base teórica y, a su vez, un elemento integrador del conjunto. Este modelo que reforzaba la idea de colectividad, y aunque conllevase una cierta dosis de idealismo utópico, fue en realidad un reflejo de una actitud social y política, donde todos los componentes del grupo pudieran sentirse cocreadores de la obra. A su vez, el colectivismo se presentó como un medio que pudiera cambiar también el sistema teatral, consiguiendo una nueva concepción de la creación escénica, unida a nuevos lenguajes escénicos y hasta una nueva manera de concebir el hecho teatral. El propio grupo lo define de la siguiente manera: "[...] trabajar en cooperativa, pero no solo en su aspecto económico, sino también en lo que significa trabajar en equipo, es decir eliminar al autor como estrella, al actor como estrella y al director como estrella" (Galán, 1971: 42).

Dentro de esta línea, hay que subrayar que en todos los grupos existían liderazgos, más o menos definidos, que influían de diferentes maneras la práctica global de los conjuntos. Si en el aspecto económico y administrativo el sistema fue claro y apenas cuestionado, en las cuestiones artísticas las discrepancias eran mayores. Tal y como indica Fermín Cabal (1980: 42), en algunos grupos la personalidad del líder provocaba rupturas dentro del colectivo, en otros, mejor integrados, aparecía un núcleo base que garantizaba la estabilidad del grupo. Este fue el caso del TEl, donde estaba claro que el líder del grupo, aunque nunca de manera explícita, fue José Carlos Plaza, que dirigió dentro del colectivo doce espectáculos. William Layton, otra persona importante del grupo, realizó seis montajes. Con el tiempo Plaza y Layton, junto con varios actores como Begoña Valle o Francisco Vidal, constituyeron una base estable que, independientemente de los cambios, avalaba la existencia del TEl.

Después de los dos primeros estrenos el TEl decide dar vida otra vez a su primer montaje realizado con el TEM: Historia del zoo, de Edward Albee. La obra se presentó el 3 de 
noviembre de 1971 en el Pequeño Teatro Magallanes. Los actores fueron José Carlos Plaza como Peter y Antonio Llopis como Jerry. Historia del zoo permaneció en cartel hasta el 12 de mayo de 1972. Durante los meses de marzo y abril, los días entre los lunes y sábados estaban reservados para salir con la pieza a distintas ciudades, mientras que los domingos el grupo volvía a Madrid y la representaba allí. La obra se repuso del 6 al 25 de septiembre de 1972. Además, entre 1973 y 1974 la Historia del zoo recorrió varios pueblos y ciudades. En 1973 Plaza y Llopis recibieron la medalla de plata de los Premios Ciudad Valladolid por su interpretación en la pieza. El seguimiento que la crítica dispensó a la obra, a su montaje y organización fue exhaustivo, y su recepción, en términos generales, muy elogiosa. Basta revisar la opinión de los contertulios en El espectador y la crítica. Francisco Álvaro confiesa salir boquiabierto de la representación de la obra:

No hay hipérbole si digo que la interpretación de Carlos Plaza y Antonio Llopis —aquél con sus actitudes y sus despistes y asombrados interrogantes, su expresividad, en suma; éste con su bla, bla minucioso e inquietante - me pareció antológica. Porque interpretar quiere decir (y perdónense la redundancia) identificarse con el texto, sentirle, gozarle o sufrirle y hacer que el espectador le goce o padezca. En esta representación de Historia del zoo la comunicación no es tópico. Insisto. Vayan ustedes a verlo (Álvaro, 1972: 266).

El colectivo no tarda mucho en montar su próxima obra y el 17 de enero de 1972 estrena una pieza de Arthur Kopit ¡Oh papá, pobre papá, mamá te ha metido en el armario ya mí me da tanta pena! El estreno de la obra significó un acontecimiento de bastante interés en la vida teatral española. Si, en general, el drama norteamericano no era desconocido en los escenarios españoles, el caso de Arthur Kopit es un descubrimiento bastante tardío y no muy explorado por el teatro español. Como prácticamente en todos los montajes del TEl, el grupo partió de la interpretación orgánica, que, además, les pareció esencial en este caso: "Porque sabíamos que solamente partiendo de la asimilación orgánica de las emociones dislocadas de los personajes por el actor, podríamos producir una aceptación catárquica del espectador hacia estos seres aparentemente lejanos e incomprensibles" (TEl, 1972: 38). La crítica, al igual que el público, se entusiasmó con la obra del TEl, alabando sobre todo la audacia del tema y la vanguardia de sus planeamientos. No obstante, en todas las críticas el análisis de la pieza de Kopit ocupa la mayor parte del texto, mientras que la reseña del montaje del TEl se resume en unas pocas frases. Por esa razón hay que reconocer que el triunfo del TEl con ¡Oh papá, pobre papá...! se da en gran medida gracias al texto del norteamericano. $Y$ aunque la realización por parte del colectivo fue muy aplaudida, el verdadero descubrimiento en este caso era Kopit. El espectáculo permaneció en cartel hasta julio del mismo año.

En mayo de 1972 el TEl estrena la obra Amantes: vencedores y vencidos, de Brian Friel: dos historias de amor contrapuestas, ahogadas por el corsé de la sociedad. El montaje fue bien acogido, sobre todo gracias a un alto nivel de interpretación, pero impopular por el tema de un entorno extraño al español, como era el intransigente ambiente irlandés.

El 25 de septiembre el colectivo presenta el resultado de su trabajo con las actrices de la Roy Hart Company (que permanecían en el Pequeño Teatro Magallanes desde principios de 1972) en una pieza de creación colectiva titulada Después de Prometeo. En la sinopsis adjunta al expediente de censura el grupo describe la obra como una pantomima con textos poéticos, sin diálogo y con mucha expresión corporal, creada a partir del texto de Esquilo y 
el mito de Prometeo ${ }^{349}$. La puesta en escena se desarrollaba fuera del escenario tradicional, los actores se situaban en forma de círculo entre los espectadores y en el transcurso de la obra se entremezclaban con el público. El espectador presenciaba una especie de ceremonia desarrollada a través de bailes, carreras, movimientos bruscos y una amplia gama de sonidos que se desenvolvían a partir de susurros y rumores hasta llegar a palabras convertidas en grito, lamento y finalmente llanto.

La crítica se mostró, prácticamente de manera unánime, impresionada por el nivel de expresionismo alcanzado en la obra. Sin embargo, las opiniones fueron ya más dispares en cuanto a la eficacia del lenguaje y la ausencia del texto literario. Por un lado, las revistas especializadas (Primer Acto, Yorick) elogiaron el montaje como uno de los mejores ejemplos de asimilación del teatro ritual. Por otro, los críticos, defensores de una comunicación más racional ( $A B C$, Nuevo Diario, Ya), clasificaron el espectáculo como confuso y ambiguo.

Aunque la obra fue autorizada para mayores de 18 años y el visado del ensayo general fue aprobado por la Delegación Provincial, tras el estreno y las publicaciones de las críticas, la censura ordena a la Delegación Provincial constantes inspecciones y solicita a la Inspección General del Ministerio el envío de tres funcionarios de la misma con el fin de poder levantar acta ante cualquier extralimitación. Los inspectores reportan que "la interpretación no se ha ajustado al texto aprobado y tan es así que más que expresión pantomímica lo ha sido de parlamento continuo, no autorizado". Para no crear un escándalo político, la Administración decide prohibir Después de Prometeo a causa de "insuficiencia de camerinos" en el local del grupo. De esta forma, el TEl se ve obligado a suspender las representaciones y rápidamente prepara, en un tiempo récord de 10 días, un nuevo estreno Historia de un soldado, de I. Stravinski.

El estreno de Después de Prometeo y su prohibición coinciden con una situación económica muy difícil del colectivo. En varios periódicos el grupo anunciaba que debía más de un millón de pesetas. Los problemas que llevaron a esta situación eran numerosos. En primer lugar, influyó de manera significativa la falta de reconocimiento de la labor del Pequeño Teatro Magallanes como válida para conseguir el carnet profesional. A pesar de la educación de varios años, avalada por años de experiencia, los actores del TEl no pudieron conseguir la aceptación del Sindicato Nacional del Espectáculo, dada la falta de la libertad sindical en el franquismo, la única organización de este tipo:

Se da la paradoja de que un actor como Antonio Llopis, que ha intervenido en los espectáculos más importantes de los últimos años (Cuento para la hora de acostarse, Proceso por la sombra de un burro, Historia del zoo), que está trabajando ininterrumpidamente desde mil novecientos sesenta y cinco y que da clases de interpretación en la Escuela de Arte Dramático, no puede tener carnet profesional porque, al parecer, no ha hecho todavía suficientes méritos (Demetrio, 1972: 39).

El segundo problema fue el del dinero, o más bien su falta, que condicionaba la vida de la sala desde sus principios ${ }^{350}$. Los problemas económicos era un asunto bastante

\footnotetext{
${ }^{349}$ El expediente de la obra se encuentra en la caja 73/9968, Sección de Cultura 3(46), del AGA. Para no multiplicar las notas, las citas referentes a la censura de la obra Después de Prometeo corresponderán al mismo expediente.

${ }^{350}$ Siguiendo los datos que aporta Fernando Cantalapiedra (1991: 122), los gastos que tenían que asumir los grupos independientes eran los siguientes: sueldo de los actores, gastos del local, gasto de transporte, gastos de puesta de escena y montaje, gastos de distribución, varios y publicidad. Además también tenían que pagar los siguientes
} 
complejo, ya que tenían su fuente en varias cuestiones vinculadas, por un lado, con las subvenciones, por otro, condicionadas por la legislación vigente. Hasta los años sesenta el teatro en España careció de protección, salvo las cuestiones de mantenimiento de los edificios teatrales y los festivales oficiales. En ambos casos el dinero fue repartido por el SNE y los certámenes nacionales. Una gran parte del dinero fue invertida en la maquinaria del aparato de censura e inspecciones de espectáculos. En el caso del TEl, la ayuda oficial fue muy escasa, por no decir inexistente: "[...] creemos que necesitamos señalar que no tenemos subvenciones estatales (al contrario, el Ministerio nos debe desde hace tres años la mitad del importe de un premio, y además, no nos favorece con las ayudas que se dan a los demás teatros cuando representan autores españoles)" (Demetrio, 1972: 39).

Después de más de un año de funcionamiento el grupo se enfrentaba a una gran crisis económica: todavía no había terminado de pagar los gastos de la instalación del local y ya había acumulado deudas. Siguiendo en la modalidad de cooperativa, cobraban, en el caso de llenar la sala todos los días, dos mil pesetas a la semana; generalmente era bastante menos. Para poder sacar estas cuentas los componentes del TEl tenían que trabajar dieciséis horas diarias, que se repartían entre los estudios, ensayos y representaciones, contando también las actuaciones fuera del Pequeño Teatro Magallanes. No fueron ya suficientes las subvenciones de amigos, que compraban unos carnets de mil pesetas al año, que daban derecho a entrar a la sala cuando se quería. En 1972 estas ayudas oscilaban entre las cien mil pesetas y las ciento veinticinco mil pesetas. Sin embargo, la mayoría de este dinero se lo quedaba la Sociedad de Autores:

Para ser teatro tenemos que tener bambalinas, telón de acero, apuntador y dos acomodadores. Y claro, nosotros no tenemos espacio para todo esto. Como no hay una reglamentación de cafés-teatro, tenemos que pagar a la Sociedad de Autores por minuto de la representación; entonces cada representación nos cuesta tres mil pesetas, mientras que cualquier teatro de verdad solo paga el diez por ciento de la taquilla. Inútil decir que en ocasiones no llegamos a esa recaudación. Por otra parte, se entiende que al pagar una cantidad fija, nos equilibramos con cualquier otro café-teatro, que puede tener cincuenta veces nuestras localidades y servicios de mariscos y whiskys durante la representación [...] (Demetrio, 1972: 39).

A su socorro llegó la Fundación Juan March que en 1973 le concedió al TEl una subvención para la investigación en el ámbito teatral con la cuota de 1.500 .000 pesetas. Sin embargo, las dificultades no desaparecieron y en realidad fueron arrastrados hasta final de la existencia del colectivo.

\section{Hacia la independencia del actor}

El montaje de Después de Prometeo marcará un momento importante en la trayectoria del TEl. La obra traza una línea de fin de búsqueda hacia la experimentación del Teatro Antropológico. Después de las representaciones de Después de Prometeo, que no dejaron indiferente a nadie y fueron tratadas como un ejemplo de los aciertos y limitaciones de la

impuestos: tráfico de empresas e IRTP como industriales, licencia fiscal, impuestos menores, sociedad de Autores, cuotas del sindicato. 
creación colectiva, el TEl no volverá a sumergirse de manera tan profunda en el teatro ritual y ceremonial. No obstante, vale la pena apuntar que esta experiencia servirá al TEl en su proceso de desarrollo. A partir de este momento, el TEl evoluciona desde un meticuloso realismo introspectivo, iniciado en la época del TEM, hasta ampliar los registros de la improvisación siempre lejos de la imitación naturalista de la realidad. En los siguientes montajes se notará un acercamiento hacia la realidad del público con toques de elementos populares, como formas circenses o carnavalescas, que marcarán la expresión escénica del grupo.

El 8 de enero de 1973 el TEl estrena su versión de Los justos, de Albert Camus. El trabajo sobre la obra de Camus fue un estudio profundo y exhaustivo de cada uno de los personajes, su psicología, su vida y sus motivaciones. Como resultado de esta labor, por un lado, el grupo sostiene el tema general de la obra, es decir, la necesidad de acomodar los medios y los fines a una misma normativa ética y la consiguiente agonía producida por el empleo de la violencia con un fin justo, localizando el conflicto en el seno del Partido Comunista. Y por otro, el grupo decide manipular el texto original para adaptarlo a sus necesidades y exigencias. Al final de la obra de Camus quedan eliminados todos los elementos que sugieren lo que Monleón llama "existencia de un orden humano, social y libre, que no permite al terrorista justificar plenamente sus actos en nombre de los fines perseguidos" (Monleón, 1973: 67). El montaje del TEl no dejó de ahondar en esta contemplación y presentó el terrorismo como la parte áspera de una acción revolucionaria necesaria para conseguir la victoria. Un cambio importante se hallaba también en el epílogo, donde una voz en off anunciaba: "Doce años más tarde triunfará la revolución", frase que fue interpretada como una opinión del TEl de que todas las acciones de la célula quedaban justificadas e inmersas en el reto y el proceso hacia esa victoria. Los justos recibieron en general muy buenas críticas, seguidas por gran entusiasmo del público. Aunque prácticamente todos los críticos subrayaron que la intervención en el texto lo simplificó demasiado, consideraron la obra de Camus como uno de los más destacados montajes del grupo $^{351}$.

En abril del mismo año el TEl estrena Un ligero dolor de Harold Pinter, continuando la línea iniciada con la obra de Camus de introspecciones psicológicas. Sin embargo, la obra no llegó a entusiasmar ni a la crítica ni al público. Sintiendo la recaída del interés y con necesidad de hacer taquilla, el colectivo decide reanimar su éxito de la época del TEM, Proceso por la sombra de un burro, coincidiendo con el cumplimiento de dos años de la actividad de la sala. A la hora de hacer el nuevo montaje de Dürrenmatt el TEl intentó en cierto modo desvincularse de las representaciones del TEM, subrayando sobre todo un cambio en el pensamiento sobre el concepto del teatro. Preguntados por el recuerdo que guardan de aquellas representaciones y cómo valoran aquella experiencia, responden: "Para nosotros, su único interés estuvo en que fue la primera vez que salíamos a un escenario. Por lo demás, está olvidado completamente. [...]; fue un trabajo colectivo y su importancia radicó en que con ella nos presentamos ante un público y un medio social. Nuestro concepto del teatro ha variado. No queda nada, ni ideológica ni técnicamente" (Layton, 1972: 16).

\footnotetext{
${ }^{351}$ Resulta importante señalar que ninguna de las críticas se centró en el tema del terrorismo para hacer alusión a la situación del país, ya que a principios de 1973 el tema del terrorismo no era todavía una gran preocupación en España.
} 
El 13 de abril de 1974 el TEl estrena Sticks and Bones, adaptada como Mambrú se fue a la guerra, del desconocido en aquella época en España autor estadounidense, David Rabe. El espectáculo significará para el colectivo un paso adelante en la búsqueda del lenguaje armado con los más diversos medios unidos a la libertad formal, que llevan la pieza hacia un tono violento y disparatado dentro de la línea que siempre perseguía el grupo: profunda y amarga crítica social. Yendo más allá de lo alcanzado en la obra de Kopit, el TEl apuesta por una expresión aún más exacerbada y cruel, para mostrar de forma clara la hipocresía de la sociedad. Mientras el montaje se presenta en el Pequeño Teatro Magallanes, en mayo de 1974 el TEl monta una reposición de ¡Oh, papá, pobre papá...! en el Teatro Benavente de Madrid, que con gran éxito permanece en cartel hasta junio.

En agosto el colectivo decide volver a realizar la obra de Brecht que al principio de su actividad fue prohibida nada más estrenarse. Para el estreno de Terrory miseria del III Reich el TEl decidió volver al escenario del Teatro Benavente. En 1974 y 1975 la obra estuvo de gira por trece ciudades españolas y se encontró con actitudes de todo tipo. En Madrid, el grupo recibió llamadas insultantes y numerosos anónimos, uno de ellos firmado por el grupo neonazi CEDADE. Además, en enero de 1975, un grupo de desconocidos prendió fuego a un bidón, ante la puerta del teatro Capsa de Barcelona, en donde se representaba la obra del TEl. Estas amenazas aumentaron de cierto modo la atracción del espectáculo y la obra se convirtió en un éxito de público por toda España, donde la asistencia fue numerosa y muy entusiasta.

La obra de Brecht traerá una discusión alrededor del trabajo del TEl y la aplicación del Método, que sembró dudas desde los inicios del grupo. Los fundamentos del trabajo del TEl, establecidos anteriormente por el TEM, estaban situados en la veracidad de actuación del actor. El camino más eficaz que ha encontrado el TEl para lograr este supuesto era la técnica de improvisación, entendida como un procedimiento que se basa en el conflicto dramático. Para el TEl cada interpretación del actor era un conflicto o una lucha que intentaba elevar lo que la naturalidad pudo tener de dramático. En este aspecto, el trabajo del TEl y de su laboratorio fue enteramente monopolizado por el actor, que se convertía en un protagonista indiscutible del hecho teatral. Su intento de descubrir su verdad interna era la única manera de poder llegar a comunicarse de modo auténtico con el espectador:

No nos interesa el teatro representado clásico, sino el conseguir que el actor sienta al máximo su papel; que viva auténticamente lo que es ficción como única forma de comunicación con el espectador. En el momento en que el actor cree realmente lo que representa y sufre en consecuencia, el mensaje llega con facilidad. El medio de llegar al público es entonces mucho más emocional que cerebral. En todo este proceso intervienen multitud de técnicas, que son las que estamos estudiando y experimentando continuamente (Espinos, 1973:31).

EI TEl tenía muy claro que ya no se trataba de generar mecanismos de imitación teatral, sino descubrir los procesos de la comunicación: "No hacemos teatro por estética, ni para formar actores perfectos, ni para investigar nuevas formas... Lo hacemos para comunicar al público una actitud, unas ideas" (Espinos, 1973: 31). En este aspecto, el grupo dotó de una especial importancia el concepto de subtexto introducido por Stanislavski. Los componentes del TEl estaban convencidos de que una creación dramática ocultaba varios matices que estaban por descifrar y por desarrollar. William Layton lo veía de la siguiente 
manera: "Yo me pregunto: ¿por qué presentar en un teatro lo que ocurre todos los días en el metro? Porque sabemos que allí hay un mundo de subtexto. Lo que se ve no es la verdad. ¿Para qué presentarlo entonces? Lo interesante es lo que no se ve. Descubrir esto es lo importante" (Layton, 1972: 29). El descubrimiento venía por medio de técnicas cercanas al psicoanálisis, en las que el actor trataba de encontrar sus propias emociones, para por este medio, como dice José Carlos Plaza, "quitarle la careta" y llegar a una liberación interna: "Solo queremos ver lo que cada actor tiene dentro. Si esto es liberatorio, doloroso, agresivo, angustioso o maravilloso y da mucha paz es una cuestión aparte. Lo que sí es cierto es que trabajando en un personaje puedes llegar a ver en ti mismo unos mecanismos que a ese personaje le van, y ese descubrimiento puede servirte, si no como liberación, al menos como información" (Galán, 1971: 43).

La comunicación eficaz se convirtió en una de las bases y objetivos del trabajo del TEl: "Como grupo, nuestro objetivo consiste en contar algo determinado a mucha gente, y de la forma que haga más fácilmente asimilable el mensaje de la obra" (Espinos, 1973: 31). Preguntados por el tipo de teatro que pretendían realizar los componentes del TEI, respondían:

A un artista en un principio, no se le ocurre nada por obra y gracia de algún otro espíritu; el artista es un trabajador por encargo, aunque a veces no sea consciente de cómo se le encarga el arte. Pensamos que nuestro teatro debe estar encaminado a comunicarnos con todo tipo de público, y para establecer esta comunicación debemos tener presentes las vivencias de todos los componentes de la sociedad.; en definitiva tratamos de mostrar la realidad en la sociedad española actual, lo cual no quiere decir que esté presente en su totalidad en un espectáculo (Medina Vicario, 1976:394).

Junto con este fin, la motivación más importante fue para el grupo el compromiso ético:

Nosotros queremos hacer espectáculos consecuentes con nuestros planteamientos, atender a nuestras circunstancias y al desarrollo de lo que venimos haciendo, sin saltos gratuitos y puramente miméticos. En este sentido, el TEl ha sido criticado muchas veces, simplemente porque no nos hemos adscrito a las modas; eso nos ha hecho parecer un "ente aparte" catalogados como reaccionarios o gentes metidas en su urna. Eso es falso. Lo que es que antes de hacer alguna cosa nos la planteamos con mucho rigor. Si eso es una situación muy cómoda, o si estamos equivocados no lo sabemos. [...] Nos preocupa mucho ser consecuentes con nuestros espectáculos (Layton, 1972:22).

Según pasaban los años, el propio TEl intentaba separarse de la etiqueta del grupo del Método, sobre todo en su faceta dogmática. Basta revisar los reportajes y entrevistas con el grupo, para ver cómo los componentes del colectivo insisten en no aplicar siempre las doctrinas del Método a su trabajo: "iEs que el Método del TEl no es el Método! Yo solo sé de Strasberg algunas pocas cosas que he leído. El Método del TEl es una cosa muy especial, en constante evolución. La pena es que no debe verse fuera" (Layton, 1972: 26). De ahí que el TEl intente alejarse de la visión de estar dentro de un sistema cerrado o un dogma e insista en nombrar su trabajo como interpretación orgánica u organicidad del actor. Según el 
director, solo había un factor que unía a todos los montajes del grupo: intención de una comunicación teatral emocional y sensitiva por medio de la presencia física del actor en el escenario. José Carlos Plaza da esta definición de la técnica que perseguía el grupo, ya unos años después de su disolución: "El método para nosotros solo consiste en una cosa: en la organicidad del actor, la verdad del actor sobre el escenario. Intentamos que nuestros actores estén constantemente improvisando, entendiendo por tal el trabajo según los impulsos que recibe de su propia provocación y de las de los demás, dentro de un molde y un estilo" (Oliva, 1980: 163).

Sin embargo, había muchas perplejidades alrededor de este tema. Una de las cuestiones fundamentales fue el asunto de la aplicación de las técnicas utilizadas por TEl a los textos, cuya poética no siempre se ajustaba a los conceptos del trabajo orgánico. Varios eran los juicios opuestos, que no se creían las explicaciones ofrecidas por el grupo y que denunciaron la falta de una base ideológica coherente que tuviera como un verdadero objetivo la renovación del panorama teatral. Entre los más descontentos con los resultados del grupo se encontraba Ricard Salvat, que acusaba al TEI de falta de verdaderas propuestas dramatúrgicas. En su artículo sobre la temporada teatral 1974 en Barcelona, describe de la siguiente manera al colectivo madrileño:

Un cierto teatro llamado independiente ha puesto en marcha un cierto teatro llamado colectivo o de creación colectiva, en el cual todo parece posible. Basado en la demagogia y en unos lugares comunes que son siempre los mismos; ataque a la religión, ataque a la familia, ataque a la dictadura, y con unos procedimientos de exasperación del público se intenta dar un espectáculo que se pretende crítico, pero, que en el fondo, se permite todos los excesos (Salvat, 1975: 265-267).

Por lo demás, Salvat acusa al TEl de interpretar a todos los autores con las mismas características, apuntando directamente en la aplicación del Método: "El TEl tiene un estilo a medio camino del sainete y del método stanislavskiano exasperado y lo aplica por igual a todos los autores. En su trabajo no había ninguna investigación, ninguna preocupación de revisión dramatúrgica, nada, solo la preocupación de lucimiento de unos actores" (Salvat, 1975: 265-267).

El TEl defendía su posición con dos argumentos. En primer lugar, José Carlos Plaza siempre repetía que "la improvisación es un medio para conseguir un resultado" y nunca al revés. Segundo, convencía que "el espectáculo que ofrecemos nunca es de Albee o de Kopit, ni de Layton o de Plaza, sino del grupo, del TEl" (Layton, 1972: 24). Además, el director confesaba que en muchas ocasiones las diferencias en cómo funcionaban las obras, no se encontraban en la imposibilidad de aplicarles el trabajo orgánico, sino en la preparación del actor. Como uno de los ejemplos Plaza señalaba las desigualdades entre la Historia del zoo y ¡Oh, papá, pobre papá...! donde consideraba que el equipo que trabajó en la segunda obra no fue tan bueno como el que interpretó los personajes de la primera. En este sentido, el problema no estaba en la técnica sino en la preparación técnica de los actores: "[...] hay que tener en cuenta que la obra funciona no porque esté adaptada al Método, sino porque el actor que la lleva —y no hablo de mí, claro— trabaja en el Método desde hace nueve años. Si ese actor hubiera hecho Kopit, es seguro que el $i O h$, papá...! hubiera funcionado de otra forma" (Layton, 1972: 24). 
Siguiendo esta línea de explicaciones, el director negó la unidad de técnica y de forma en las diferentes producciones del colectivo, refiriéndose a la falta de un procedimiento establecido para los montajes del grupo. Plaza veía el objetivo común del trabajo de la compañía en el camino hacia la comunicación teatral emocional y sensitiva, dentro de la cual un lugar primordial ocupaba el poder de la comunicación que posee la presencia física del actor:

Nosotros no tenemos un punto de partida fijo sino que cambiamos del Método en cada obra. Y nos cuesta mucho. Eso es lo que quería explicar. Es muy probable que el resultado no se vea. Pero te aseguro que nuestro único principio consciente es que cada cosa que pasa en el escenario tiene que pasar en ese momento. Ya exista o no un punto de vista histórico o crítico, el espectador nunca debe pensar que le están "contando una historia", sino que está "viéndola". La que ese espectador ve es verdad y el actor, aunque está criticando, está haciéndolo ahí (Layton, 1972: 26).

En la defensa de los trabajos del TEI Plaza también recurría a la evolución constante en la que estaba el colectivo. Los autores y obras que elegían para sus siguientes montajes, aunque no fuesen piezas directamente aplicables a las técnicas de interpretación orgánica, eran para el director una prueba del progreso del grupo, que estaba en una constante búsqueda de nuevas vías de expresión. Dentro de esta búsqueda se encontraba una tensión, provocada por un lado, por las exigencias del texto original y por otro, por las exigencias de organicidad. Esta tensión fue que en cierto modo el punto de partida para muchas de las investigaciones del TEl. Plaza explicaba este mecanismo con el ejemplo del montaje de Amantes: vencedores y vencidos: “[...] en la próxima obra que montaremos, [...], apoyaremos una parte dentro de las vivencias de los personajes y la otra en un punto de vista crítico orgánico. Y es muy posible que no funcione bien, porque no tenemos la técnica desarrollada, pero en ningún momento será porque el Método del TEl intente chuparse la obra" (Layton, 1972: 26).

A finales de noviembre de 1974 el TEl realiza Súbitamente el último verano, de Tennessee Williams. La obra, muy atrevida en su propuesta escénica (el escenario no contenía ninguna referencia al tiempo ni lugar definidos, colocando al espectador en un espacio y tiempo míticos que existían dentro del armazón del artificio escénico), no se encontró con buena recepción ni por parte del público ni de la crítica. Lázaro Carreter, de la Gaceta llustrada, clasifica el espectáculo como desprovisto de sustancia crítica o auroral. El crítico considera que la intención de proponer algo valioso para el espectador español del año 1974 se queda únicamente en la intención: "la expectación queda defraudada, la esperanza se esfuma, y hasta el respeto se tambalea por la sospecha vehementísima de que la promesa de ideología es mero cebo para el espectador y coartada para el grupo" (Álvaro, 1975: 54).

\section{Cierre del Pequeño Teatro Magallanes}

En el año 1975, cuando el mantenimiento de la sala se hace cada vez más difícil desde el punto de vista económico, el grupo decide no montar nada nuevo y pasa el año de la ya mencionada gira por provincias con la obra de Brecht. En junio las representaciones se muestran también en el Pequeño Teatro Magallanes. 
El siguiente estreno del grupo es Cándido ${ }^{352}$, sin embrago la obra ya no se presentó en la sala Magallanes, que entra en su fase de crisis. Las causas de estas dificultades no fueron nada diferentes de las ya descritas, que tuvieron lugar en 1972. En realidad, los apuros económicos que perseguían la compañía eran continuos y se centraban en serias dificultades para mantener el equilibrio entre los gastos y los ingresos de la sala.

En marzo de 1976 el TEl lanzaba un comunicado en el que llamaba la atención sobre su difícil situación. En varias fuentes las cifras de la deuda son diferentes y oscilan entre trecientos mil pesetas hasta un millón de pesetas. Ante la amenaza del cierre del local el grupo solicitó al Ministerio de Información y Turismo que el Pequeño Teatro Magallanes fuese considerado como centro de interés cultural, a nivel de los cines de Arte y Ensayo, y de esta manera pudiera liberarse de impuestos y contar con la ayuda de parte de los organismos oficiales. La petición sin embargo quedó sin respuesta. Como último recurso, el 6 de marzo de 1976, el TEl decide reponer durante tres semanas en el Teatro Barceló Proceso por la sombra de un burro, para poder ganar el dinero necesario para pagar la deuda. Luego la obra se presenta durante dos semanas también en el Pequeño Teatro Magallanes.

Sin embargo, estos esfuerzos no fueron suficientes y el TEl se encontró ante la orden judicial que les daba tiempo hasta primeros de julio de 1976 para pagar la deuda, o en caso contrario se cerraba el local. El día final llegó el 8 de julio, cuando a las nueve de la mañana los funcionarios del Juzgado número 22 de Madrid procedieron al desalojo del local y su cierre definitivo. El día 13 de julio de 1976 el diario El País recoge el último comunicado del TEl sobre su sede:

[...] este cierre se une y vuelve a poner de manifiesto la situación insostenible de tantos trabajadores de la cultura, la incomprensión, el desamparo e incluso el desprecio y la ineficacia con que los organismos de la Administración controlan la acción de la cultura y denuncia "el cerco económico a que este local ha estado sometido". Por todo ello, reclaman y exigen "una administración política teatral democráticamente elegida por los miembros de nuestra profesión, la libre utilización de todo tipo de local público para el hecho teatral, y de los medios de comunicación pública, la abolición de la censura en todas sus formas de expresión, y sobre todo la consideración por parte del Gobierno de que el teatro es un servicio público para nuestro país". "Todo esto —dicen- Ilevaría consigo la inmediata ruptura de la legalización actual, que solo beneficia a un número determinado y mínimo de empresarios teatrales, en su mayoría propietarios o arrendatarios de los locales legalizados del país" (Pereda, 1976: en línea).

En general, la prensa acogió la noticia del cierre del Pequeño Teatro Magallanes como un triste final de un intento memorable, abortado por la ineficacia y falta de interés por parte de la Administración. Desde Barcelona, Antonio Valencia en La Vanguardia describía el Pequeño Teatro Magallanes como un refugio de una serie de actuaciones que no tenían cabida en los recintos comerciales y donde "el teatro no convencional experimental y de ruptura siempre tenía luz encendida allí". En opinión de Valencia, la programación de la sala

\footnotetext{
${ }^{352}$ El espectáculo basado en el Cándido, de Voltaire, es una obra que marca una nueva etapa en la trayectoria del TEl, la última y la más corta en la vida del grupo. Los ensayos para la pieza empezaron todavía en el Pequeño Teatro Magallanes, pero perdida la sala, el TEl decidió continuar con el Cándido, esta vez como prueba de sobrevivencia de la compañía. En Madrid Cándido se estrenó el día 3 de septiembre de 1976, en el Teatro Lara, acogido por la prensa de manera desigual, aunque con el dominio de críticas positivas.
} 
fue "ejemplarmente coherente en la presentación de un teatro vocacional y de ruptura que únicamente podría verse alli" (Valencia, 1976: 48). Rosa M. Pereda en El País resumía la iniciativa del Pequeño Teatro Magallanes como un intento de crear un centro de actividades teatrales y culturales independientes "siempre en una doble selección: ideológicamente progresivos, demócratas, con ideas socialistas, en un amplio espectro. $Y$ artísticamente, buscando la calidad artística, la novedad, la aportación experimental" (Pereda, 1976: en línea). Diego Galán describía la sala como "el único intento que en nuestro país se creaba con una total coherencia y con unas amplias posibilidades de trabajo" (Galán, 1976: 46). Aunque el periodista incluye algunas palabras de crítica, en seguida hace constar que estas no cambian la totalidad de importante trabajo que ejerció la sala para la escena española:

Cierto es que la programación ofrecida durante estos cinco años no ha sido siempre excelente. Pero tampoco tenía por qué serlo. De lo que se trataba era de abrirse a proyectos insólitos en nuestro panorama teatral. [...] Lo que nunca ha ocurrido en el Pequeño Teatro es que se nos ofreciera un teatro viejo exento de inquietudes, y si alguna vez ha habido algún error en este sentido, fue siempre indiscutible el interés apriorístico que ese programa en concreto tenía (Galán, 1976: 46).

El novedoso planteamiento de la sala fue además apoyado por importantes cambios introducidos en su funcionamiento. Siendo los primeros en la profesión, los actores del TEI desde el principio de la actividad de la compañía han implantado un día de descanso (los lunes). Los demás actores tuvieron que esperar hasta 1972, cuando después del despido de Juan Diego y Concha Velasco, por exigir el día de descanso, la profesión se movilizó y la propuesta terminó por ser aceptada por la patronal. Fue también el primer grupo independiente que a partir de la segunda quincena de enero de 1972 empezó a insertar publicidad de sus espectáculos en prensa. Asimismo, el Pequeño Teatro Magallanes fue pionero en introducir el intercambio de espectáculos entre los grupos independientes. En aquella época fue una práctica novedosa, ya que hasta 1995 no se institucionaliza por medio de la creación del Circuito Intersalas, que permite que las compañías con local propio intercambien sus trabajos. En este sentido, el local del TEl era una plataforma de presentación, no solo de los montajes del propio colectivo, sino también de numerosos grupos invitados, como La Cuadra, Tábano, Compañía de Repertorio Norteamericano, Esperpento, Compañía María Paz Ballesteros, Ensayo Uno-En Venta, Teatro Libre. La variedad y calidad de la oferta de la sala fue galardonada con el premio de El espectador y la crítica en 1972 por la mejor programación de una sala comercial. El Pequeño Teatro Magallanes vuelve a ser nominado en la misma categoría en 1974, sin obtener el premio.

Inminentemente surge la pregunta, si el Pequeño Teatro Magallanes hubiese aguantado unos años más, establecida ya la democracia, ¿habría mantenido la sala? La respuesta se encuentra en el ejemplo de la madrileña Sala Cadarso. El local fue abierto a principios de 1976 con el objetivo de crear un espacio donde los grupos independientes pudieran ofrecer diariamente sus representaciones. Como detalla Monleón, en el momento de la apertura de la sala, "el proyecto es serio, porque uno de los problemas esenciales de nuestro teatro independiente ha sido siempre la falta de locales, solamente abiertos —salvo en Colegios Mayores y alguna otra excepción- a los grupos del mejor nivel" (Monleón, 1976: 73). Durante sus años de funcionamiento en una plata baja de un centro escolar, el Gobierno Civil de Madrid en varias ocasiones dictaminó el cierre de la sala, ya que según la 
reglamentación vigente ${ }^{353}$ carecía de las condiciones materiales que se exigían para un local de espectáculos. La sala sufrió en total tres clausuras gubernativas y cerró definitivamente en junio de 1982, por dificultades técnicas y económicas.

Así, llegaba una nueva época que para todo el movimiento significaba momento de un examen, un ajuste de cuentas y un balance de su actividad. El Estado empezaba a hacerse cargo del teatro no comercial y asumía las propuestas más audaces. En esas condiciones un teatro marginal y provocador empezaba a perder gran parte de su sentido. Ante la pérdida del local de Magallanes, la mala acogida de la siguiente obra Preludios para una fuga ${ }^{354}$ y el cambiante panorama político y social el TEl decide tomar la decisión de cambio. Así, nace un nuevo capítulo en la vida del grupo: el Teatro Estable Castellano (TEC).

\section{REFERENCIAS BIBLIOGRÁFICAS}

ALONSO DE SANTOS, J. L. (1981). "El Método en España. Entrevista con William Layton". Primer Acto 188 (febrero-junio), 17-29.

ÁLVARO, F. (ed.) (1972). El espectador y la crítica, el Teatro en España en 1971. Madrid: Prensa Española.

(1973). El espectador y la crítica, el Teatro en España en 1972. Madrid: Prensa Española.

(1974). El espectador y la crítica, el Teatro en España en 1973. Madrid: Prensa Española.

(1975). El espectador y la crítica, el Teatro en España en 1974. Madrid: Prensa Española. (1976). El espectador y la crítica, el Teatro en España en 1975. Madrid: Prensa Española.

BÚFALO (1974). "Para un análisis del teatro independiente en España”. Pipirijaina 4 (junio), 1-2.

CABAL, F. (1980). "La creación colectiva en el teatro español”. Primer Acto 183 (febrero), 3446.

CANTALAPIEDRA, F. (1991). El teatro español de 1960 a 1975: estudio socioeconómico. Kassel: Reichenberger (con prólogo de José Romera Castillo).

CIURANS, E. (2003). "El Teatre Independent. Estat de la qüestió". Assaig de teatre: Revista de I'Associació d'Investigació i Experimentació Teatral 37, 13-19.

CORNAGO BERNAL, Ó. (2000). Discurso teórico y puesta en escena en los años sesenta: en la encrucijada de los realismos. Madrid: CSIC.

DEMETRIO, E. (1972). “EI TEl. ¿Reinar después de morir?”. Triunfo 523 (7 de octubre), 39.

DÍAZ SANDE, J. R. (1980), "William Layton y el TEC levantan el telón para un autor español: Alfonso Vallejo". Reseña 124 (enero-febrero), 16-19.

ESPINOS, R. (1973). “EI TEI, un grupo". La Vanguardia (30 de diciembre), 31.

\footnotetext{
${ }^{353}$ El nuevo Reglamento de Espectáculos no entra en vigor hasta el 27 de agosto de 1982, cuando se publica el Real Decreto 2816/1982 por el que se aprueba el Reglamento General de Policía de Espectáculos Públicos y Actividades Recreativas.

${ }^{354}$ La obra fue creada a base de textos de Máximo Gorki, J. J. Rousseau (sin determinar ningunos en concreto), fragmentos de la prensa diaria y textos propios de la compañía. Se componía de cuatro partes, denominadas por el grupo como ambientes que se relacionan dentro del argumento global y dividen como movimientos de una partitura. La obra se estrenó en Madrid el 11 de noviembre de 1977, en el Teatro Valle Inclán, bajo la producción de Manuel Collado. La crítica acogió el espectáculo del TEl elogiando la eficacia y la calidad unida a alto nivel interpretativo, pero prácticamente todos los críticos incluyeron dudas, algunas muy serias, en cuanto al uso del teatro a servicio de la política
} 
FERNÁNDEZ INSUELA, A. (1975). "Notas sobre el teatro independiente español”. Archivum 25, 303-322.

FERNÁNDEZ TORRES, A. (coord.) (1987). Documentos sobre el Teatro Independiente Español. Madrid: Centro Nacional de Nuevas Tendencias Escénicas (Colección Teoría Escénica 2).

GALÁN, D. (1971). “El TEl, una nueva mentalidad”. Triunfo 480 (11 de diciembre), 42-44.

_(1976). "Adiós, adiós, Pequeño Teatro". Triunfo 694 (15 de mayo), 46-47.

LAYTON, W. et alii (1972). "Mesa redonda: el TEl, historia y método". Primer Acto 142 (marzo), 10-31.

LÓPEZ GÓMEZ, M. (1965). "Nuestro trabajo en el TEM". Primer Acto 66, 5-7.

MEDINA VICARIO, M. (1976). El teatro español en el banquillo. Valencia: Fernando Torres.

MONLEÓN, J. (1970a). "I Festival Internacional de San Sebastián. Consideraciones autocríticas sobre un festival interrumpido". Primer Acto 120 (mayo), 56-65.

_ (1970b). "Encuesta sobre el Festival Cero de San Sebastián”. Primer Acto 25 (octubre), 24-26.

_ (1973). "Los justos, de Camus, por el TEl". Primer Acto 153 (febrero), 66-67.

_ (1976). “Un local para el teatro independiente”. Triunfo 689 (10 de abril), 72-73.

OLIVA, C. (1980). "Una tertulia con José Carlos Plaza, con el TEC y el Corral de Almagro al fondo". Primer Acto 183 (febrero), 159-167.

PEREDA, R. M. a (1976). "Cierra el Pequeño Teatro". El País (13 de julio). En línea: http://elpais.com/diario/1976/07/13/cultura/206056804_850215.html [consulta: 18/02/2012].

PÉREZ COTERILLO, M. (1974). “Teatro Independiente: ¿Hacia un futuro mejor?". Reseña 77 (febrero), 22-23.

PÉREZ JIMÉNEZ, M. (1999). "Apuntes para el estudio de la creación teatral española durante el siglo XX. (Presentación esquemática del método historizador de Ángel Berenguer)". Las Puertas del Drama 0 (otoño), 4-17.

POBLACIÓN, P. (1971). "La sesión". En Teatro español, 1969-1970, F. C. Sáinz de Robles (ed.), 305-307. Madrid: Aguilar.

ROMERA CASTILLO, José (2011). "Sobre un teatro (en) vivo: el nuevo teatro en la escena madrileña (1970-1974)". En su obra, Pautas para la investigación del teatro español y sus puestas en escena, 320-334. Madrid: UNED.

SALVAT, R. (1963). "10 años de Teatro Independiente (Agrupación de Teatro Experimental. Teatro Vivo. EADAG)". Primer Acto 45, 8-11.

(1975). "Juicio de valor sobre el teatro en Barcelona en 1974". En El espectadory la crítica, el Teatro en España en 1974, F. Álvaro (ed.), 245-272. Madrid: Prensa Española.

SÁNCHEZ SÁNCHEZ, J. P. (1997). "La escena madrileña entre 1970 y 1974". Teatro: Revista de Estudios Teatrales 12, 9-328.

TEI (1971). "Pequeño Teatro (TEI), vital laboratorio escénico". ABC (11 de noviembre), 132133.

_(1972). "Montaje de Oh papá, pobre papá". Primer Acto 142 (marzo), 38-39.

VALENCIA, A. (1976). "Necesidad de los teatros estables". La Vanguardia (29 de mayo), 48.

Recibido el 29 de abril de 2014.

Aceptado el 23 de septiembre de 2014. 